Case Report

\title{
Lonomia obliqua Accident and Anesthesia
}

\author{
André Keng Wei Hsu ${ }^{1,3 *}$, Nathalia Beller ${ }^{2}$, Gabriela Bassani Fahl $^{1}$ and Norma Sueli Pinheiro Modolo ${ }^{3}$ \\ ${ }^{1}$ Universidade Regional Integrada de Erechim, Faculdade de Medicina (URI-Erechim), Brazil \\ ${ }^{2}$ George Washington University (GWU-Washington, DC), Brazil \\ ${ }^{3}$ Universidade Estadual de São Paulo, Botucatu, Departamento de Anestesiologia (UNESP-Botucatu), Brazil
}

*Corresponding author: André Keng Wei Hsu, Universidade Regional Integrada de Erechim, Faculdade de Medicina (URI-Erechim), Brazil

Received: March 09, 2021; Accepted: March 15, 2021; Published: March 23, 2021

\begin{abstract}
The case of a 45-year-old man who presented with extreme pain and edema after having touched a Lonomia obliqua caterpillar is described. Accidents due to the brief contact with this caterpillar may lead to a severe coagulopathy, hemorrhage, and death. Thus, it is important to discuss the mechanism of envenomation caused by the caterpillar. Antivenom treatment serum most commonly used to treat Lonomia accidents is highlighted and further described.
\end{abstract}

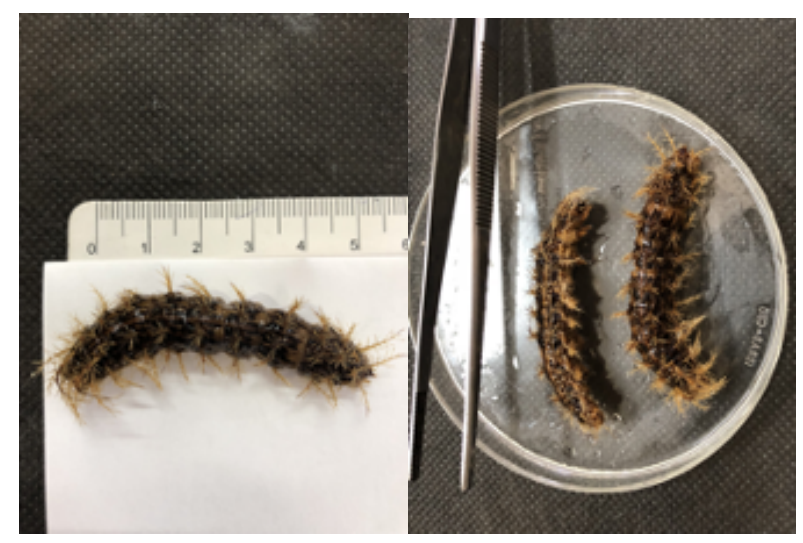

Images from Science Museum of URI Erechim (RS)-Brazil

\section{Introduction}

Lonomia obliqua is a species of caterpillar most commonly found in the Southern part of Brazil. This caterpillar is also known as the "fire insect" because the hair covering its body contains toxic venom that is absorbed through the skin of a victim when its spine is broken. This envenomation causes intense pain in the location of absorption, disseminated intravascular coagulation, renal failure, and a consumptive coagulopathy, which can lead to a hemorrhagic syndrome and death [1-4].

\section{Case Report}

The patient who entered the emergency room was a 45 -year-old man with extreme pain and edema in the ankle and left calf. He had no history of trauma and his symptoms started slowly two days prior. The patient had no foot pulse, the compartment syndrome diagnosis was made, and a fasciotomy was necessary. The anesthesiology staff did not know that the Lonomia accident had occurred and performed a 27 gauge pencan spinal anesthesia. The surgery went well and the blood flow returned to the foot. Six hours after the surgery, the patient had fully recovered from anesthesia but started presenting extreme blood loss in the leg wound. Blood samples showed 9.3 RNI, 130000 platelets and 4.3 creatinine. Neurological examination was performed every 6 hours without alterations. The patient was in anuria since he was admitted to the hospital. Despite the efforts of volume resuscitation, he had the effect of the venom in association with muscle damage in the leg, causing rhabdomyolysis and leading to renal failure. After a long inquisition, it was discovered that he worked with wood, where this type of caterpillar resides, and treatment with Lonomia Antivenom (LAV) began. The antivenom is the most effective treatment for Lonomia obliqua accidents and is only produced by the Butantan Institute in Sao Paulo. This antivenom is made by the filtration of immunoglobulins produced by horse serum [2,5-7]. The vitals of the patient became stable, the bleeding stopped, and all his test results were normal in 36 hours, including renal function [2].

\section{Discussion}

Lonomia accidents are very dangerous and can lead to disseminated intravascular coagulation. This happens because the venom modulates the expression and phosphorylation levels of migration-related proteins, making the cells show an increased 
membrane ruffling (meaning a decreased cell adhesion), a decrease in the velocity of cell protrusions, and a more rounded shape, all resulting in a lower polarity index [5]. Spontaneous bleeding shown by the patient is due to systemic vascular and inflammatory disorders generated by the venom [5]. The venom is composed of molecules that may act directly or contribute to the generation of endogenous mediators, such as kinins, chemokines, and cytokines, that can induce vascular injury. The venom also has a direct effect on Vascular Smooth Muscle Cells (VSMC), inducing oxidative stress and the modification of the functionality of these cells [6]. Specifically, the venom consists of procoagulant toxins, such as factors II and X activators, but studies have shown that it does not consist of fibrinolytic activity. These toxins produce a coagulation cascade involving a prothrombin activator known as Lopap, which activates prothrombin, resulting in the production of thrombin that may cause fibrinogen to promote clot formation $[3,8,9]$. Previous research has revealed that an increase in intravascular thrombin concentration due to a Lonomia accident may disrupt endothelial cells, resulting in a hemorrhagic condition [5].

As the lethality of the venom is 1.5 to $2.0 \%$, the patient is likely to die or suffer from systemic complications if no treatment is provided [1]. The antilonomic serum therapy has shown to be the most effective treatment for lonomic envenomation because previously tested therapies, including whole blood replacement, have revealed that there is an increase in coagulation due to the higher amount of clotting factors and toxins in the bloodstream. The antigen provided in the antivenom (antilonomic serum) only uses the scoli extracts and is effective in neutralizing the toxins involved in the envenomation by triggering $\lg G$ antibody production [7,9]. Precisely, the antivenom is an isotonic solution that has been purified by enzymatic digestion. The serum antibodies bind specifically to the venom, which is not yet fixed in the cells, causing it to be neutralized [10].

Several studies have determined that the serum aids in the recovery of fibrinogen and normalizes levels of thrombin, prothrombin, and activated partial thromboplastin, reverting hemostatic complications [8]. Patients who are diagnosed early and treated within the first 12 hours are less likely to develop severe coagulopathy and are able to recover within 20 hours of treatment [1,9]. Additionally, neuraxial block is contraindicated in these patients. If a patient came from this endemic region and started showing spontaneous bleeding, it is always important to remember that this accident may have occurred before anesthesia or surgery [3].

\section{References}

1. Sano-Martins IS, Duarte AC, Guerrero B, Moraes RHP, Barros EJG, et al. (2017) Hemostatic disorders induced by skin contact with Lonomia obliqua (Lepidoptera, Saturniidae) caterpillars. Rev Inst Med Trop Sao Paulo 59: e24.

2. Caovilla Jairo, Barros Elvino (2004) Efficacy of two different doses of antilonomic serum in the resolution of hemorrhagic syndrome resulting from envenoming by Lonomia obliqua caterpillars: A randomized controlled trial. Toxicon: official journal of the International Society on Toxicology 43: 811-818. [crossref]

3. Alvarez Flores M, P Zannin M, Chudzinski-Tavassi A (2010) M: New Insight into the Mechanism of Lonomia obliqua Envenoming: Toxin Involvement and Molecular Approach. Pathophysiol Haemos Thromb 37: 1-16.

4. Zanon P, Pizzato SB, da Rosa RL, Terraciano PB, Moraes JA, et al. (2021) Urine proteomic analysis reveals alterations in heme/hemoglobin and aminopeptidase metabolism during Lonomia obliqua venom-induced acute kidney injury. Toxicol Lett 341: 11-22. [crossref]

5. Bernardi L, Pinto AFM, Mendes E, Yates JR 3rd, Lamers ML (2019) Lonomia obliqua bristle extract modulates Racl activation, membrane dynamics and cell adhesion properties. Toxicon 162: 32-39. [crossref]

6. Moraes João A, Rodrigues Genilson, Nascimento-Silva Vany, Renovato-Martins Mariana, Markus B, et al. (2017) "Effects of Lonomia obliqua Venom on Vascular Smooth Muscle Cells: Contribution of NADPH Oxidase-Derived Reactive Oxygen Species" Toxins 9: 11: 360. [crossref]

7. Sano-Martins IS, Gonza'lez C, Anjos IV, D1'az J, Gonc, alves LRC (2018) Effectiveness of Lonomia antivenom in recovery from the coagulopathy induced by Lonomia orientoandensis and Lonomia casanarensis caterpillars in rats. PLoS Negl Trop Dis 12: e0006721. [crossref]

8. Gonçalves LRC, Sousa-e-Silva MCC, Tomy SC, Sano-Martins IS (2007) Efficacy of serum therapy on the treatment of rats experimentally envenomed by bristle extract of the caterpillar Lonomia obliqua: Comparison with epsilon-aminocaproic acid therapy. Toxicon 50: 349-356. [crossref]

9. Chudzinski-Tavassi AM, Carrijo-Carvalho LC (2006) Biochemical and biological properties of Lonomia obliqua bristle extract. Journal of Venomous Animals and Toxins Including Tropical Diseases 12: 159-171.

10. INSTITUTO BUTANTAN. Coordenadoria de Ciência, Tecnologia e Insumos Estratégicos de Saúde. Secretaria de Estado da Saúde. Governo do Estado de São Paulo. Soro antilonômico: bula profissional.

\section{Citation:}

Wei Hsu AK, Beller N, Fahl GB, Modolo NSP (2021) Lonomia obliqua Accident and Anesthesia. Integr J Anesth Sur Volume 2(1): 1-2. 